\title{
Migration to middle-income countries and tuberculosis-global policies for global economies
}

\author{
Julia Moreira Pescarini ${ }^{1,2^{*}}$, Laura Cunha Rodrigues², M. Gabriela M. Gomes ${ }^{3,4,5}$ and Eliseu Alves Waldman ${ }^{1}$
}

\begin{abstract}
Background: International migration to middle-income countries is increasing and its health consequences, in particular increasing transmission rates of tuberculosis (TB), deserve consideration. Migration and TB are a matter of concern in high-income countries and targeted screening of migrants for active and latent TB infection is a main strategy to manage risk and minimize transmission. In this paper, we discuss some aspects of TB control and migration in the context of middle-income countries, together with the prospect of responding with equitable and comprehensive policies.
\end{abstract}

Main body: TB rates in middle-income countries remain disproportionally high among the poorest and most vulnerable groups in large cities where most migrant populations are concentrated. Policies that tackle migrant TB in high-income countries may be inadequate for middle-income countries because of their different socioeconomic and cultural scenarios. Strategies to control TB in these settings must take into account the characteristics of middle-income countries and the complexity of TB as a disease of poverty. Intersectoral policies of social protection such as cash-transfer programs help reducing poverty and improving health in vulnerable populations. We address the development of new approaches to improve well-established strategies including contact tracing and active and latent TB screening as an 'add on' to the existing health care guidelines of conditional cash transfer programs. In addition, we discuss how it might improve health and welfare among both poor migrants and locally-born populations. Authorities from middle-income countries should recognise that migrants are a vulnerable social group and promote cooperation efforts between sending and receiving countries for mitigation of poverty and prevention of disease in this group.

Conclusions: Middle-income countries have long sent migrants overseas. However, the influx of large migrant populations into their societies is relatively new and a growing phenomenon and it is time to set comprehensive goals to improve health among these communities. Conditional cash transfer policies with TB screening and strengthening of DOTS are some strategies that deserve attention. Reduction of social and health inequality among migrants should be incorporated into concerted actions to meet TB control targets.

Keywords: Tuberculosis, Migration, Health equity, Low- and middle-income countries

\section{Background}

Tuberculosis (TB) rates have declined significantly in the 20th century worldwide, but HIV and multidrug-resistant tuberculosis (MDR-TB) have had drastic effects in some of the poorest countries $[1,2]$. TB burden is still much

\footnotetext{
* Correspondence: juliapescarini@gmail.com.br

${ }^{1}$ Faculdade de Saúde Pública, Universidade de São Paulo, Av. Dr. Arnaldo, 715, São Paulo, SP 01246-904, Brazil

${ }^{2}$ Department of Infectious Disease Epidemiology, Faculty of Epidemiology and Public Health, London School of Hygiene and Tropical Medicine, Keppel St, London WC1E 7HT, UK

Full list of author information is available at the end of the article
}

higher in the poorest economies and highly concentrated among vulnerable ${ }^{1}$ populations and specific groups such as homeless people, people living with HIV (PLHIV), prisoners and migrants $[1,3]$. It has been a century of reawakening concerns about TB control and rebuilding strategies for the next decades.

TB and TB/HIV coinfection partially reflects the income and development level of a country, with medium incidence rates at least 20 times higher in low-income countries (LIC) than in high-income countries (HIC) (Fig. 1) $[1,4]$. Incidence of TB and associated mortality 


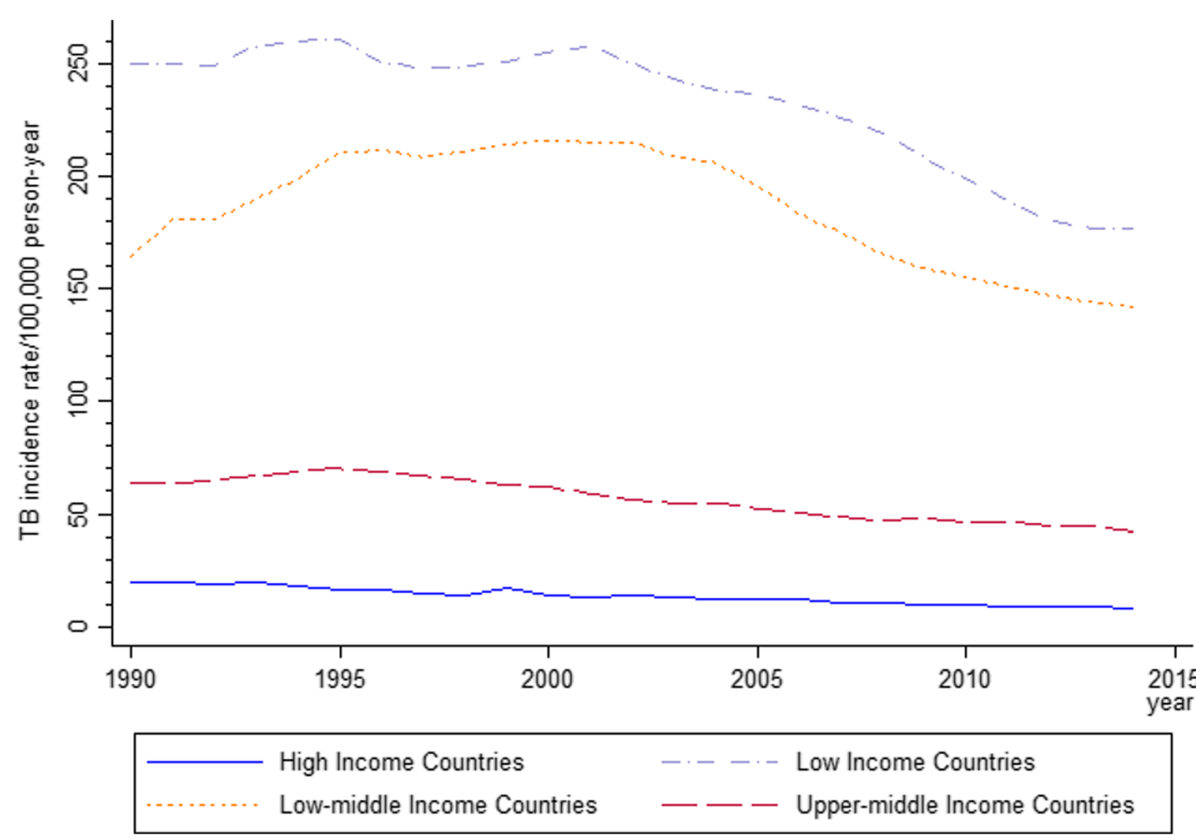

Fig. 1 Median TB incidence rate/100,000 person-year for each group of country (High, Upper-middle, Low-middle and Low-Income Countries) 1990-2014. "Median incidence was calculated using panel data, collapsing countries and calculating the median TB incidence by group of country/year. Source: Tuberculosis data extracted from WHO [1]. World Bank [4] was used to classify country groups

are now low in most HIC, with TB risk being disproportionally high among migrants from high burden countries-up to $80 \%$ of cases reported in some receiving countries [5]. Migrants are a risk group for TB from the perspective of the receiving country as TB incidence rates among them usually reflect $\mathrm{TB}$ incidence in the country of origin [6].

In HIC, migrants from high $\mathrm{TB}$ burden countries typically maintain higher active TB prevalences compared to the local population and, TB prevalence can reach at 3.3/1000 among migrants [7]. It may reflect a higher proportion of latent TB infection (LTBI) and increased risk of disease reactivation potentially increasing the risk of transmission to local communities. Migrants are often a hard-to-reach group, and thus poses a major challenge for TB control in high-income countries.

Over the last 15 years, the economic development of Upper-middle income countries (UMIC), especially the BRICS (Brazil, Russia ${ }^{2}$, India, China and South Africa) [1], has led to an increase in health spending and strengthening of primary care services [8]. Many regions have either achieved or made gains in achieving the TBrelated Millennium Development Goals [1], but in contrast to the developed world, TB rates in some countries have remained high due to sustained poverty and poor living conditions [9]. Today, a great difference in TB rates remains between UMIC and Low-middle Income countries (LMIC) (Fig. 1).
Most South American countries have robust TB control programs, but inner-city populations often live in areas of deprivation with high unemployment rates and high rates of TB-related morbidity and mortality [1]. This is common even in countries with sound economic development such as Argentina, Brazil and Chile that attract a high number of regional migrants from other middle-income countries [10-12]. Migration and TB control strategies in middle-income countries, especially in UMIC, need further investigation taking into consideration this context.

\section{Migration, vulnerability and TB}

As part of economic globalization, since the 1980s there has been an intensification of migration. Migrants living in developing regions accounted for $42 \%$ of total migration stock in 2015 and South-South ${ }^{3}$ migration now comprises $36 \%$ of total migration, a proportion that is higher than that of South-north migration [13]. Figure 2 shows total number of migrants by country according to UN [13]. Refugees from conflict areas and natural disasters are highly visible in the media, but half of the migration stock (106 million) are international labour migrants who may live in an irregular situation in the receiving country [14]. Violence, labour exploitation and sexual harassment are frequently reported as occurring during the migration journey and in the country of destination [2, 14]. Stressful conditions and social vulnerability can contribute to the 


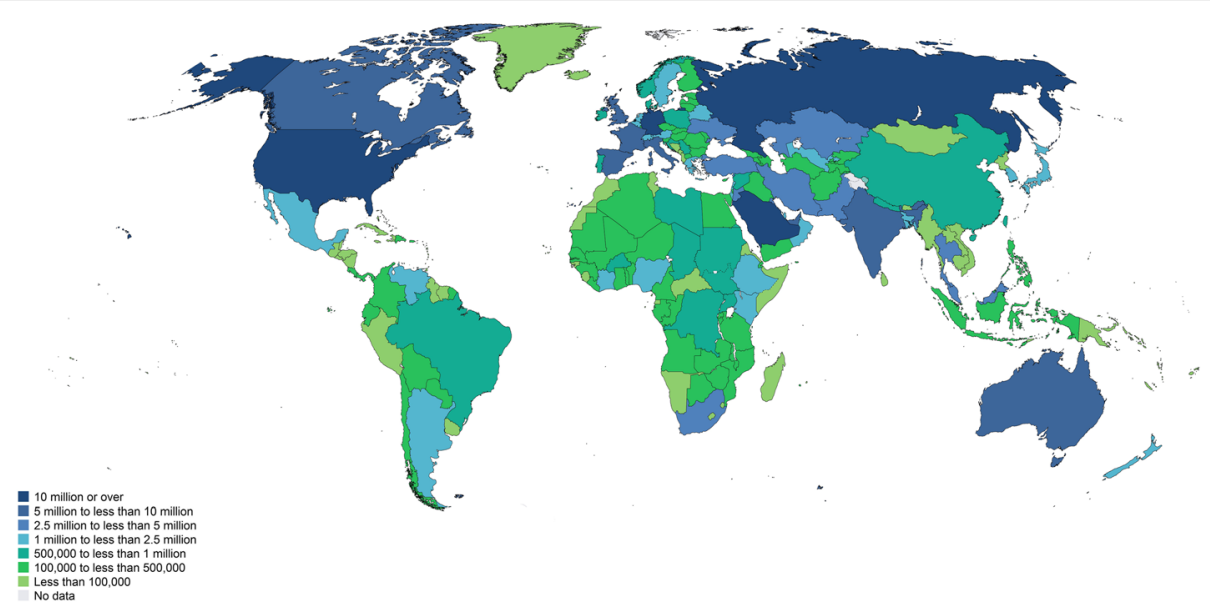

Fig. 2 Number of international migrants in 2015. Source: Adapted from United Nations (UN, [13])

development of non-infectious and infectious diseases in migrants, including TB infection or LTBI reactivation $[15,16]$.

Host societies are increasingly concerned with social and economic impacts of migration including potential effects on morbidity and mortality and the burden on health care services (especially when accurate migration data are not available) [14]. The recent international financial crisis and austerity policies in the developed world have accentuated social inequities and affected migrants disproportionately [15].

Migration in middle-income countries is generally directed to major cities [17, 18]. Migrants are more likely to settle in low-income inner-city neighbourhoods with the greatest TB burden and some migrant groups often face more poverty, vulnerability and social exclusion than native communities living in the same areas [19]. In large cities in middle-income countries with large inequalities and high proportions of HIV, homeless individuals and drug users [1,5], migrants comprise a new risk group for TB burden that needs to be specifically targeted.

\section{Tuberculosis control among migrants}

\section{Screening for active and latent TB infection}

In addition to strengthening Direct Observed Treatment, Short-Course (DOTS) strategy and Bacillus CalmetteGuérin (BCG) vaccination among migrants since the 1980s, many high-income countries with low TB burden have also incorporated active and latent TB screening. TB screening strategies directed to migrants are aimed to reduce TB burden and the risk of TB transmission: migrant screening for LTBI is estimated to prevent many new TB cases [20], potentially reducing the risk of transmission in the community whereas screening for active TB is thought to prevent more severe forms of $\mathrm{TB}$ and reduce treatment costs [21]. There is no consensus on the most appropriate screening strategy: screening for active TB and/or LTBI; pre-arrival, post-arrival or screening in the community; use of chest X-rays (CXR) and/or IGRA [5]. Screening strategies based on TB incidence in the country of origin or on the type of migration-asylum seekers/refugees-is also a common approach [22]. The cost-effectiveness of each screening strategy is determined by TB epidemiology in the country of origin or type of migration [16].

While some HIC have chosen compulsory screening for some types of migrants, others do not consider screening [22]. The decision for not performing screening is usually motivated by lack of financial aid, low yield in areas with high presence of irregular migrants (who are less frequently screened), and ethical considerations [22, 23].

The strategies for $\mathrm{TB}$ control in migrant populations in middle-income countries are poorly discussed in the literature. TB control in middle-income countries is more complex due to multifaceted problems such as poverty, inequality and higher infectious disease rates in locally born populations. It is known that the prevalence of LTBI is likely to be higher in low- and middle-income countries than in high-income countries. In Brazil, active and latent $\mathrm{TB}$ screening is only suggested for contacts of TB patients, for HIV-infected individuals, the homeless and prisoners (and treatment for LTBI is not always recommended) [24]. The estimated prevalence of LTBI was $60 \%$ among contacts of TB patients living in urban areas [25]. To consider migrants from high-incidence TB countries as risk groups for $\mathrm{TB}$ and to target them for screening may result in increased case detection and treatment coverage. But in contrast to high-income countries, screening for active TB and even LTBI in migrants in low- and middle-income countries may be more critical as incidence in migrants might be as high as that seen in poor inner-city populations $[10,26]$. 
Another issue is that targeting migrants may have a discriminatory effect. Moreover, irregular migrants may not respond to these policies for fear of detection and criminal conviction or expulsion [27]. In order to overcome potential resistance to screening, free access to treatment and hospital admissions for TB cases among migrants must be guaranteed regardless of migration status [28].

\section{Tuberculosis diagnosis and treatment among migrants}

TB-related Millennium Development Goals have brought substantial improvements in implementation of free diagnosis and TB treatment [1]. In Brazil, it was suggested that adding an intensive screening of household contacts of TB patients for active or latent TB infection to DOTS would reduce by $15 \%$ TB incidence in 5 years [25]. It further suggests that the strengthening of existing tools, as suggested in DOTS-though not fully implemented in several countries-might be effective in improving $\mathrm{TB}$ diagnosis and treatment in high-risk groups including migrants.

Although the proportion of cases of $\mathrm{TB}$ among migrants in middle-income countries is unknown, we estimate they account for a small proportion of cases. Few studies estimated the burden of TB among migrants in MIC, although migration has been increasingly important for disease control [26, 29-31], especially among the poorest and most vulnerable migrants. Institutional and skilled capacity to assist migrants need to be strengthened to deal with increasing migration flows from higher TB burden countries to large urban centres in MIC to ensure the provision of quality health care. However, the level of this demand is not yet clearly understood.

Free access to TB diagnosis and treatment has been implemented among migrants in many high-income countries, but access to health care can be especially difficult. Migrants face many social and cultural barriers to accessing treatment and sometimes they experience prejudice in health care settings [15]. Policies of free and universal access to health ensuring access for migrants has been a determinant for health equity promotion among South American migrants in large urban centres in Brazil [26]. Health care programs targeting specific groups in Latin American countries have contributed to improved access to health care [32], but the capacity of non-universal health systems to provide care to migrants may still be subjected to the current policy of a given country.

MDR-TB is currently a major challenge for TB control [1]. Migration from regions with high rates of MDR-TB is inevitable and potential issues must be addressed when planning control strategies. High coverage of drug susceptibility test (DST) among migrant populations must be achieved. MDR-TB rates are low in the Americas, which contrasts with high rates observed in sub-Saharan Africa and India [1]. Mathematical models have been increasingly built to understand TB transmission and health and economic impact of new tools and strategies for $\mathrm{TB}$ control including those for MDR-TB detection and treatment [33].

It is crucial for TB control to consider the characteristics of migrants in MIC, their interaction and social impact on host societies. Heterogeneity in TB incidence across different risk groups has been suggested as playing an important role in maintaining disease transmission, indicating that universal control measures are doomed to have limited impact if social inequalities are maintained $[11,34]$.

\section{Social protection policies}

Conditional cash transfer programs have been successfully implemented in several high-, middle- and low-income countries in the past decade. Although inclusion criteria and benefits vary, these programs are usually integrated into education and health care policies. For example, the Brazilian conditional cash transfer (CCT) program "Bolsa Família" [35] provides families who have a per capita monthly income below USD 50 with a monthly stipend per child under 18. This is conditional on children attending school and family members seeking preventive care. This policy has had a positive impact on nutrition and food security of families, maternal and child mortality, utilization of health care services, and social determinants of some infectious diseases such as leprosy $[35,36]$. The Mexican conditional cash transfer program "Oportunidades" has also had a positive impact on health outcomes and vaccination coverage among elders [37].

Few studies have focused on the impact of social protection policies on infectious disease burden, especially TB burden. Experimental provision of food baskets was associated to increased TB treatment completion and cure rates in Brazil [38]. There is also evidence showing a 7\% higher cure rate among "Bolsa Família" beneficiares in Brazil [39], and a positive impact of social protection interventions (CRESIPT project) on catastrophic cost in poor households in Peru [40]. Siroka et al. [40] also suggested a strong negative correlation between expenditures as gross domestic product (GDP) percentage in social protection programs for poverty alleviation and TB rates (for incidence, prevalence and mortality) [41].

There is lack of data about social protection policies among migrants, but we suggest that poor migrants should be offered what is offered to poor locally born people. In Mercosul ${ }^{4}$, migrants have the same rights as nationals [42] and legal residents in Brazil can access CCT programs if poverty criteria are met, but irregular migrants, which could include person with free 
movement but under irregular labour conditions, continue to be poorer and neglected. Non-criminalization of migration is an essential effort to give migrants an opportunity to improve their economic status and consequently their health. To extend social protection benefits to migrants who meet delimited poverty criteria during TB treatment will improve migrant and community health. We suggest that social protection could be integrated into control programs and active TB screening among household contacts for example act as conditionalities. These actions must assure confidentiality to guarantee the absence of additional barriers to employment and protect migrants from being deported after treatment completion.

In middle-income countries with marked social inequalities such as Brazil, control strategies would be more successful if they take into account the intricacies of $\mathrm{TB}$, placing control policies within the broader context of health care and social equity. Despite differences between public policies to promote social and health equity in Brazil and the circumstances in other middle-income countries, we believe that social protection policies must incorporate TB control strategies and a migration-related component. Migrants' sociodemographic aspects, TB morbidity and mortality and migratory patterns specific to each country must be taken into account.

\section{The advantages of an intersectoral approach to control TB among migrants}

The United Nations post-2015 agenda established more ambitious health targets and called for intersectoral policies. Since TB is a disease of poverty, predominantly affecting people living in large cities, and recognizing the wide heterogeneity existing between middle-income countries and source countries of migrants, from labour migrants to refugees, it is key to establish TB control programs alongside intersectoral public policies that promote social equity. Conditional cash transfer programs integrated into active $\mathrm{TB}$ screening and strong contact tracing could have a positive impact on TB control among the poorest and most vulnerable populations.

Cooperation and technology transfer among the BRICS and other low- and middle-income countries would also advance the control of neglected diseases [43]. These countries have reached agreements for cooperation and technology transfer for the control of neglected diseases, which points to greater integration and sharing innovation to the production of health inputs for TB control programs [43]. Some technical agreements between South American countries mediated by $\mathrm{PAHO} / \mathrm{WHO}$ have given support to improve public primary health care programs in Paraguay and in the Andes regions [44]. Such strategies could be an example to other South-South cooperation initiatives.
These notable initiatives could be expanded to include more specific targets for TB control, as improving health care may not be sufficient to guarantee equity in access for migrants. Old and new TB control strategies may not have the desired impact unless there are initiatives for poverty reduction and early disease diagnosis among migrants. Moreover, because middle-income countries have limited health care resources, established health policies may be compromised if there is an increased demand due to migration and intersectoral policies are not planned.

\section{Conclusions}

Middle-income countries and especially UMIC have been facing the same phenomena as seen in highincome countries in past decades: labour migration to large urban cities. Because of marked inequalities, big cities from middle-income countries must prepare to provide health care to incoming migrants, building on the reverse experience of being primarily a source of migration to more developed regions. In this context, intersectoral TB control strategies are needed to address social and health inequalities taking into account both migrants and locally born vulnerable groups in these countries. Conditional cash transfer policies may benefit poor migrants, especially during the first years after migration, and improve access to health care. Strengthening of DOTS and TB screening must also include migrants, especially irregular migrants that might not be supported by CCT programs. Finally, since migration flows largely take place within or between neighbouring regions [45], innovative control measures integrated with intersectoral and international policies are crucial for TB control and must be prioritized in regional agreements. Sending and receiving nations should channel their efforts to further integrating their health policies.

\section{Endnotes}

${ }^{1}$ Although difficult to define, vulnerable groups include communities that are more vulnerable to conflicts, health conditions or economic shocks: people living in extreme poverty or socially excluded individuals, migrants or specific populations such as children, women and people with disabilities.

${ }^{2}$ Russia is part of the BRICS group though it has been classified as high-income since 2013 and as uppermiddle again in 2016.

${ }^{3}$ Among a variety of definitions, "South" generally denotes low- to middle-income countries while "North" refers to high-income countries.

${ }^{4}$ Mercosur full members include Argentina, Brazil, Bolivia, Paraguay, Uruguay and Venezuela. Associate members include Chile, Peru, Colombia, Ecuador, Guyana and Suriname (Mercosul, [46]). 


\section{Abbreviations}

BRICS: Brazil, Russia, India, China, South Africa; CXR: Chest X-rays; DOT: Directly observed treatment, short-course; HIC: High income countries; HIV: Human immunodeficiency virus; IGRA: Interferon gamma release assay; LIC: Low income countries; LMIC: Low-middle income countries; LTBI: Latent tuberculosis infection; MDR-TB: Multidrug resistance tuberculosis; PLHIV: People living with HIV; TB: Tuberculosis; UMIC: Upper-middle income countries

\section{Acknowledgements}

None.

\section{Funding}

JMP and EAW received funding from the National Council for Scientific and Technological Development (CNPq) of Brazil. MGMG was supported by FCT and CAPES (Science without Borders).

\section{Availability of data and materials}

Not applicable.

\section{Authors' contributions}

JMP and EAW conceptualized and wrote the manuscript. LCR and GG made substantial contributions to the discussion, writing and editing of this manuscript. All authors have read and approved the final version of this manuscript.

\section{Authors' information}

JMP is an infectious disease epidemiologist and is currently working on tuberculosis transmission in Sao Paulo, Brazil. She is affiliated to School of Public Health/Faculdade de Saúde Pública of Universidade de São Paulo and to the London School of Hygiene and Tropical Medicine. LCR is an infectious disease epidemiologist, Professor at the London School of Hygiene and Tropical Medicine. MGMG is a Professor at the Liverpool School of Tropical Medicine and is also affiliated to CIBIO-InBIO in Portugal and to the Instituto de Matemática e Estatistica of Universidade de São Paulo, Brazil. EAW is an infectious disease epidemiologist, Professor at School of Public Health/Faculdade de Saúde Pública of Universidade de São Paulo. He is an associate editor of several Brazilian journals and a member of the Committee of Brazilian National Surveillance System Evaluation.

\section{Competing interests}

The authors declare that they have no competing interests.

\section{Consent for publication}

Not applicable.

\section{Ethics approval and consent to participate}

Not applicable.

\section{Author details}

'Faculdade de Saúde Pública, Universidade de São Paulo, Av. Dr. Arnaldo, 715, São Paulo, SP 01246-904, Brazil. ²Department of Infectious Disease Epidemiology, Faculty of Epidemiology and Public Health, London School of Hygiene and Tropical Medicine, Keppel St, London WC1E 7HT, UK. ${ }^{3}$ Liverpool School of Tropical Medicine, Pembroke Place, Liverpool L3 5QA, UK. ${ }^{4} \mathrm{CIBIO}-$ InBIO, Centro de Investigacao em Biodiversidade e Recursos Geneticos, Universidade do Porto, Rua Padre Armando Quintas, $n^{\circ} 7$, Vairão 4485-661, Portugal. ${ }^{5}$ Instituto de Matematica e Estatistica, Universidade de São Paulo, R. do Matão, 1010 - Vila Universitaria, São Paulo, SP 05508-090, Brazil.

Received: 27 May 2016 Accepted: 3 February 2017

Published online: 15 March 2017

\section{References}

1. WHO. Global tuberculosis report 2015. Geneva: World Health Organization; 2015.

2. UNDP. Human development report 2014. Sustaining human progress: reducing vulnerabilities and building resilience. New York: United Nations Development Programme; 2014.

3. UNAIDS. The cities report 2014. Geneva: Joint United Nations Programme on HIV/AIDS; 2014
4. The World Bank Group. World Bank Country and Leading Groups. World Bank list of economies, Washington. 2016. http://databank.worldbank.org/ data/download/site-content/CLASS.xls. Accessed 20 Sept 2016.

5. Alvarez G, Gushulak B, Rumman K. A comparative examination of tuberculosis immigration medical screening programs from selected countries with high immigration and low tuberculosis incidence rates. BMC Infect Dis. 2010;11:3.

6. van der Werf MJ, Lönnroth K. Pre-entry, post-entry, or no tuberculosis screening? Lancet Infect Dis. 2014;14(12):1171-2.

7. Aldridge RW, Yates TA, Zenner D, White PJ, Abubakar I, Hayward AC. Pre-entry screening programmes for tuberculosis in migrants to lowincidence countries: a systematic review and meta-analysis. Lancet Infect Dis. 2014:14(12):1240-9.

8. Rao KD, Petrosyan V, Araujo EC, McIntyre D. Progress towards universal health coverage in BRICS: translating economic growth into better health. Bull World Health Organ. 2014;92(6):429-35.

9. Barreto ML, Teixeira MG, Bastos Fl, Ximenes RA, Barata RB, Rodrigues LC. Successes and failures in the control of infectious diseases in Brazil: Social and environmental context, policies, interventions, and research needs. Lancet. 2011;377(9780):1877-89.

10. Riley LW, Ko Al, Unger A, Reis MG. Slum health: diseases of neglected populations. BMC Int Health Hum Rights. 2007;7:2.

11. Dowdy DW, Golub JE, Chaisson RE, Saraceni V. Heterogeneity in tuberculosis transmission and the role of geographic hotspots in propagating epidemics. Proc Natl Acad Sci U S A. 2012;109:9557-62

12. Ritacco V. The Situation of HIV/Mycobacterium tuberculosis Co-Infection in South America. Open Infect Dis J. 2011:5:81-8.

13. United Nations, Department of Economic and Social Affairs. Trends in International Migrant Stock: The 2015 revision. New York. 2016. http://www. un.org/en/development/desa/population/migration/data/estimates2/data/ Number\%20of\%20international\%20migrants.zip. Accessed 2 Nov 2016.

14. IOM. World Migration Report 2013. Migrant well-being and development Genava: International Organization for Migration; 2013.

15. Hemminki K. Immigrant health, our health. Eur J Public Health. 2014;24(S1):92-5.

16. Pareek M, Greenaway C, Noori T, Munoz J, Zenner D. The impact of migration on tuberculosis epidemiology and control in high-income countries: a review. BMC Med. 2016;14(1):1-10.

17. IOM. South America: The regional migration context. International Organization of Migration. Regional Office for South America. 2016. https://www.iom.int/south-america. Accessed 1 Feb 2016

18. Strand $M$, Xiaobing $W$, Xiaogin $D$, Lee $K$, Wang $A$, Yanqing $L$, et al. Presence and awareness of infectious disease among Chinese migrant workers. Int Q Community Health Educ. 2007;26(4):379-95.

19. Silveira C, Carneiro Junior N, Ribeiro MC, Barata Rde C. Living conditions and access to health services by Bolivian immigrants in the city of São Paulo, Brazil. Cad Saude Publica. 2013:29(10):2017-27.

20. Panchal RK, Browne I, Monk P, Woltmann G, Haldar P. The effectiveness of primary care based risk stratification for targeted latent tuberculosis infection screening in recent immigrants to the UK: a retrospective cohort study. Thorax. 2014;69(4):354-62.

21. Arshad S, Bavan L, Gajari K, Paget SNJ, Baussano I. Active screening at entry for tuberculosis among new immigrants: a systematic review and meta-analysis. Eur Respir J. 2010;35(6):1336-45.

22. Pareek M, Baussano I, Abubakar I, Dye C, Lalvani A. Evaluation of immigrant tuberculosis screening in industrialized countries. Emerg Infect Dis. 2012;18(9):1422-9.

23. Abarca Tomás B, Pell C, Bueno Cavanillas A, Guillén Solvas J, Pool R, et al. Tuberculosis in migrant populations. A systematic review of the qualitative literature. PLOS ONE. 2013:8(12):e82440.

24. Secretaria de Vigilância em Saúde. Manual de recomendações para o controle da tuberculose no Brasil. Brasil: Brasilia: Ministerio da saude: 2011

25. Cavalcante SC, Durovni B, Barnes GL, Souza FBA, Silva RF, Barroso PF, et al. Community-randomized trial of enhanced DOTS for tuberculosis control in Rio de Janeiro, Brazil. Int J Tuberc Lung Dis. 2010;14(2):203-9.

26. Martinez VN, Komatsu NK, Figueredo SM, Waldman EA, De Figueredo SM, Waldman EA. Equity in health: tuberculosis in the Bolivian immigrant community of Sao Paulo, Brazil. Trop Med Int Health. 2012;17(11):1417-24.

27. Coker R, Bell A, Pitman R. Tuberculosis screening in migrants in selected European countries shows wide disparities. Eur Respir J. 2006;27(4):801-7. 
28. Chemtob D, Srour SF. Epidemiology of HIV infection among Israeli Arabs. Public Health. 2005;1 19(2):138-43.

29. Godfrey-Faussett P, Sonnenberg P, Shearer SC, Bruce MC, Mee C, Morris L, et al. Tuberculosis control and molecular epidemiology in a South African gold-mining community. Lancet. 2000;356(9235):1066-71.

30. Moosazadeh M, Khanjani N, Bahrampour A, Nasehi M. Does tuberculosis have a seasonal pattern among migrant population entering Iran? Int J Health Policy Manag. 2014;2(4):181-5.

31. Ventura E. TB migration in Southern Africa. World TB Day - especial IOM newsletter. 2016.

32. Vega J, Frenz P. Latin America: priorities for universal health coverage. Lancet. 2015;385(9975):e31-2.

33. Zwerling A, White RG, Vassall A, Cohen T, Dowdy DW, Houben RMGJ. Modeling of novel diagnostic strategies for active tuberculosis A systematic review: Current practices and recommendations. PLoS One. 2014;9(10):e110558.

34. Gomes MGM, Barreto ML, Glaziou P, Medley GF, Rodrigues LC, Wallinga J, et al. End TB strategy: the need to reduce risk inequalities. BMC Infect Dis. 2016;16(1):1-4

35. Rasella D, Aquino R, Santos CAT, Paes-Sousa R, Barreto ML. Effect of a conditional cash transfer programme on childhood mortality: a nationwide analysis of Brazilian municipalities. Lancet. 2013;382(9886):57-64.

36. Nery JS, Pereira SM, Rasella D, Penna ML, Aquino R, Rodrigues LC, et al. Effect of the Brazilian conditional cash transfer and primary health care programs on the new case detection rate of leprosy. PLoS Negl Trop Dis. 2014:8(11):e3357.

37. Salinas-Rodríguez A, Manrique-Espinoza BS. Effect of the conditional cash transfer program Oportunidades on vaccination coverage in older Mexican people. BMC Int Health Hum Rights. 2013;13:30.

38. Torrens AW, Rasella D, Boccia D, Maciel EL, Nery JS, Olson ZD, et al. Effectiveness of a conditional cash transfer programme on TB cure rate: a retrospective cohort study in Brazil. Trans R Soc Trop Med Hyg. 2016:110(3):199-206

39. Wingfield T, Tovar MA, Huff D, Boccia D, Montoya R, Ramos E, et al. The economic effects of supporting tuberculosis-affected households in Peru. Eur Respir J. 2016;48(5):1396-410

40. Siroka A, Lönnroth $\mathrm{K}$, Ponce $\mathrm{N}$. The impact of social protection on tuberculosis rates: a global analysis. Lancet Infect Dis. 2016;16(4):473-9.

41. Cantalice Filho JP. Food baskets given to tuberculosis patients at a primary health care clinic in the city of Duque de Caxias, Brazil: effect on treatment outcomes. J Bras Pneumol. 2009;35(10):992-7.

42. Cernadas PC. Migration, citizenship and free movement in south america: a rights-based analysis of regional initiatives. Draft paper prepared for the UNRISD conference regional governance of migration and socio-political rights: institutions, actors and processes. Geneva: United Nations Research Institute for Social Development (UNRISD); 2013.

43. Cashwell A, Tantri A, Schmidt A, Simon G, Mistry N. BRICS in the response to neglected tropical diseases. Bull World Health Organ. 2014;92(6):461-2.

44. PAHO. Cooperação Técnica entre Brasil e Paraguai para a implantação do Programa Saúde da Família no Paraguai. Brasilia: Organização Pan-Americana da Saúde/Pan-American Health Organization; 2013.

45. Abel GJ, Sander N. Quantifying global international migration flows. Science. 2014:343(6178):1520-2.

46. Mercosur. Países del MERCOSUR. http://www.mercosur.int/innovaportal/v/ 7823/4/innova.front/paises-del-mercosur. Accessed 1 Nov 2016.

\section{Submit your next manuscript to BioMed Central and we will help you at every step:}

- We accept pre-submission inquiries

- Our selector tool helps you to find the most relevant journal

- We provide round the clock customer support

- Convenient online submission

- Thorough peer review

- Inclusion in PubMed and all major indexing services

- Maximum visibility for your research

Submit your manuscript at www.biomedcentral.com/submit

) Biomed Central 